\title{
Estamos no nosso melhor momento...
}

Em nosso editorial anterior, apresentamos uma síntese da trajetória de 27 anos dos Cadernos de Terapia Ocupacional da UFSCar, lançado em maio de 1990, e da sua continuidade, a partir de junho de 2017, com o nome de Cadernos Brasileiros de Terapia Ocupacional / Brazilian Journal of Occupational Therapy, ISSN 2526-8910 (MALFITANO; CRUZ; LOPES, 2017); tal síntese, dentre outros aspectos, pontuava, para aqueles que não conhecem essa história, o nosso envolvimento plenamente consolidado com a divulgaçáo do conhecimento em terapia ocupacional, e em suas interfaces, no âmbito nacional, avançando para o cenário latino-americano e buscando contornos para uma circulação mundial.

Em meio ao intenso trabalho cotidiano que esse envolvimento demanda e também às comemorações dos pequenos avanços de cada dia, recebemos, em julho último, a importante informaçáo de que fomos indexados na Emerging Sources Citation Index-ESCI, base de dados de entrada da Web of Science, fruto da solicitação providenciada por esta editoria e pelo fato de artigos dos Cadernos já terem sido referidos por periódicos que integram a Web of Science.

Nossa indexaçấo na ESCI é um passo importante e que, certamente, poderá contribuir com o propósito comum a todos nós de que boa parte da produçáo acadêmica nacional em terapia ocupacional possa, de fato, circular entre pesquisadores, estudantes e profissionais pelo mundo.

Celebramos o alcance dessa etapa e destacamos que, dentre as 39 revistas voltadas para a divulgação do conhecimento em terapia ocupacional existentes no mundo, apenas nove possuem fator de impacto, o que decorre da entrada efetiva na Web of Science, nenhuma delas da nossa região nas Américas.

A Web of Science, base de dados mantida pela Clarivate Analytics, indexa o que considera mais importante na literatura científica mundial, conectando publicaçôes e pesquisadores, em todas as áreas do conhecimento, oferecendo, em seus termos, parâmetros para avaliação do desempenho em pesquisas de pessoas, instituiçôes, países (CLARIVATE ANALYTICS, 2017).

A indexação de citaçôes foi criada para a recuperação de informaçôes, mas ela também forneceu dados para avaliaçóes do que pode ser considerado parte do impacto de um determinado trabalho de pesquisa, com base em quáo frequentemente esse trabalho ofereceu referências para outros pesquisadores.

Um de seus pioneiros foi Eugene Garfield, químico e linguista nascido em setembro 1925, de uma segunda geração de imigrantes judeus em Nova York (EUA), e falecido em fevereiro deste ano (WAUTERS, 2017). Garfield criou o Institute for Scientific Information - ISI (EUA, 1955), além do ISI's Science Citation Index, e esteve à frente do desenvolvimento de diversos bancos de dados de citação, incluindo a Web of Science e o Journal Citation Reports, que informa fatores de impacto e outros dados de citaçôes para milhares de publicaçôes acadêmicas (THE SCIENTIST STAFF, 2017).

A despeito das críticas e polêmicas ao redor dos sistemas de classificação acadêmica, é nesse escopo de informaçóes que pretendemos manter incluído os Cadernos Brasileiros de Terapia Ocupacional, para, também, sermos ouvidos nesse debate e repercutir nossa produção.

Durante os próximos dois anos, aproximadamente, seremos monitorados pela Clarivate Analytics, a fim de que sejamos avaliados quanto à manutençáo da qualidade já demonstrada nessa primeira indexaçáo e possamos passar a integrar plenamente a Web of Science. Sendo assim, continuamos contando com o apoio de todos na participação no periódico, como leitores, difusores, autores e revisores.

Sem dúvida, para parte de nós que acompanha o trabalho da editoria dos Cadernos desde o seu lançamento, sabemos que estamos em nosso melhor momento, só comparável em pioneirismo, criatividade e importância àquele em que decidimos que a terapia ocupacional brasileira poderia enfrentar o desafio da publicação e manutenção de um periódico acadêmico.

São Carlos, inverno/primavera, 2017.

\author{
Roseli Esquerdo Lopes \\ Daniel Marinho Cezar da Cruz \\ Ana Paula Serrata Malfitano
}

Editores

Cadernos Brasileiros de Terapia Ocupacional/Brazilian Journal of Occupational Therapy 


\section{Referências}

CLARIVATE ANALYTICS. Pai fundador da Web of Science da Clarivate Analytics, Dr. Eugene Garfield, morre aos 91 anos. Disponível em: < http://www.prnewswire.com/news-releases/pai-fundador-da-web-of-science-da-clarivate-analytics-dr-eugene-garfield-morre-aos-91-anos-614996663.html>. Acesso em: 1 ago. 2017.

MALFITANO, A. P. S.; CRUZ, D. M. C.; LOPES, R. E. Cadernos Brasileiros de Terapia Ocupacional: mudando para permanecer e avançar. Cadernos Brasileiros de Terapia Ocupacional, São Carlos, v. 25, n. 2, p. 243-244, 2017. http://dx.doi.org/10.4322/0104-4931.ctoED2502

THE SCIENTIST STAFF. Scientometrics pioneer Eugene Garfield dies. Disponível em: <http://www.the-scientist. com/?articles.view/articleNo/48636/title/Scientometrics-Pioneer-Eugene-Garfield-Dies/>. Acesso em: 1 ago. 2017.

WAUTERS, P. Eugene Garfield (1925-2017). Inventor of the Science Citation Index. Nature, London, v. 543, n. 23, p. 492, 2017. 